\title{
Supply Chain Management Resources, Capabilities and Execution
}

(Published in Production Planning and Control in 2014, DOI:

10.1080/09537287.2014.927932)

Herbert Kotzab*

University of Bremen, Bremen, Germany

Christoph Teller

University of Surrey, Guildford, United Kingdom

David Grant

University of Hull, Hull, United Kingdom

\section{Anders Friis}

Aston University, Birmingham, United Kingdom

* (corresponding author) Institute for Logistics and Supply Chain Management, University of Bremen, 2000 Bremen, Germany; Tel.: +49(0)42121866981,e-mail: kotzab@unibremen.de;

Reference of the original article: Kotzab H, Teller C, Grant D, Friis A. (2014) 'Supply Chain Management Resources, Capabilities and Execution'. Production Planning and Control, in print, DOI: 10.1080/09537287.2014.927932. 


\section{Supply Chain Management Resources, Capabilities and Execution}

This paper identifies inter- and intra-organisational management resources that determine the level of execution of inter-firm alliance supply chain management (SCM). By drawing on network and resource-based view theories, a conceptual model proposes the effects of SCM resources and capabilities as influencing factors on SCM execution. The model was tested using survey data from studies conducted in two European supply chain environments. Variance-based structural equation modelling confirmed the hypothesised hierarchical order of three proposed antecedents: internal SCM resources affect joint SCM resources, which in turn influence collaborative SCMrelated processes and finally SCM execution. An importance-performance analysis for both settings shows that providing and investing in internal SCM resources should be a priority when aiming to increase SCM execution. The theoretical contribution of this paper lies in confirming that the improvement of SCM execution follows a clear pathway featuring internal supply chain resources as one of the main drivers. The practical implications of this research include the development of a prioritisation list of measures that elevate SCM execution in the two country settings.

Keywords: supply chain management, supply chain execution, resource-based view, network, structural equation modelling; 


\section{Introduction}

Today, competition occurs amongst inter-organisational vertical networks or supply chains that operate mainly in the Western world in quite saturated market environments (Wilkinson and Young 2002). Olhager (2002) pinpoints the positive effects of supply chain initiatives such as collaboration and linking on internal, upstream and downstream operations efficiency. Such initiatives refer mainly but not exclusively to the concept of supply chain management (SCM). SCM is defined as the 'co-ordination of a strategic and long-term cooperation among co-makers in the total supply chain for the development and production of products, both in production and procurement and in product and process innovation' (Schnetzler and Schönsleben 2007, 498). SCM refers also to manufacturing processes required to transform goods from raw materials into final products (Heizer and Render 2014). Offering a support function to operations strategy, SCM helps to lower transaction costs, input and output price differences, and uncertainties in terms of the supply of input factors and information asymmetry, through activities such as order processing and fulfilment production, and the setting up and maintenance of production technologies (Walters 2002; Arend and Wisner 2005). The objective of SCM is the simultaneous reduction of costs and creation of value by means of optimising customer satisfaction, assets and costs in order to maximise the supply chain's competitive advantage (Schnetzler and Schönsleben 2007; Stock and Boyer 2009; Heizer and Render 2014). This is important as, for many companies, a huge share of the costs of their manufactured goods occur externally (Nelson 2002).

Supply chain managers thus have an expanded view of process execution, consisting of not just a single isolated unit but an inter-organisational unit comprising an upstream and a downstream network (Cousins and Menguc 2006). Such quasi-integrated channels (Cai, Yang, and Hu 2009) span from raw material suppliers to the final customer (Frohlich and Westbrook 2001; Heikkilä 2002). The role of supply chain managers is to install and execute 
a set of inter-organisational business processes to add customer value and optimise the whole entity instead of single parts of it (Cooper and Ellram 1993; Cooper, Lambert, and Pagh 1997; Heikkilä 2002). The execution of SCM allows firms to work in a seamless manner and can subsequently become a strategic weapon, helping to significantly improve the overall performance of a business (Dierickx and Cool 1989; Narasimhan and Das 2001; Cook, Heiser, and Sengupta 2011; Johnson and Templar 2011). Alfalla-Luque, Medina-Lopez, and Dey (2013) argue that a firm's total performance improvement - as a consequence of SCM execution - refers to internal as well as external improvements, both of which can be achieved through resource sharing, coordination and collaboration.

However, collaborative alliances in vertical business networks such as supply chains are difficult to organise (Möller, Rajala, and Svahn 2005). The management of supply chains requires, due to their cooperative nature, more or less close relationships between the members of networks (Corbett, Blackburn, and van Wassenhove 1999). This leads to one of the core issues of SCM, which - according to Hsuan Mikkola and Skjøtt-Larsen (2004) refers to the design and development of relationships between the members of a supply chain. Cigolini and Rossi (2008) define such collaborative behaviour as 'supply chain integration' and see this as a key element in the SCM strategy (see also Alfalla-Luque, Medina-Lopez, and Schrage 2013). Palomero and Chalmeta (2012) understand this as a continuous improvement process driven by interactions and collaborations, leading to an enhanced capability for supply chain partnering. The dimensions of supply chain integration refer to the degree of collaborative inter- and intra-organisational management and are related to the strategic, tactical and operational activity levels of the management of the flow of goods and information from the raw material supplier to the final customer (Alfalla-Luque, MedinaLopez, and Dey 2013). However, these levels of integration remain unchanged despite managers' awareness of their potential benefits (Jin, Fawcett, and Fawcett 2013). 
Recently Alfalla-Luque, Medina-Lopez, and Dey (2013) and Alfalla-Luque, MedinaLopez, and Schrage (2013) have taken a critical look at the issue of supply chain integration by identifying deficiencies in the research domain in terms of heterogeneous measurement or the focus on selected integration aspects. Consequently, they derive a framework of supply chain integration that consists of three dimensions (information integration, coordination and resource sharing, and organisational relationship linkages) that are all aimed at integrating internally with suppliers as well as with customers. Some conceptual and empirical studies suggest that the level of implementation of inter-organisational supply chain business processes depends on the existence of specific SCM-related resources (Kotzab et al. 2011; Teller, Kotzab, and Grant 2012). However, the literature still lacks insights as to which resources and capabilities in individual firms directly drive and indirectly leverage their internal and external integration of supply-chain-specific business processes with suppliers and customers, creating value and improving the total performance of the chain. This individual firm level of integration or implementation is what we refer to as the degree of SCM implementation, or the execution of SCM (Faria and Wensley 2002; Cai, Yang, and Hu 2009; Kotzab et al. 2011; Baraldi, Gressetvold, and Harrison 2012; Gadde, Hjelmgren, and Skarp 2012). This understanding is different from what other streams of literature call SCM integration, which refers to the integration of SCM software with other IT/ERP systems (e.g. Tarn, Yen, and Beaumont 2002, Ivanov and Sokolov 2010).

By utilising the resource-based view (Penrose 2009; Barney 2012) within the context of vertical inter-organisational networks, the aims of this paper are (1) to discuss, conceptualise and evaluate how inter- and intra-organisational SCM resources and capabilities affect SCM execution, (2) to determine those SCM resources and capabilities that are key to improving the SCM execution in firms, and finally (3) to identify similarities in effects and areas for improvement across different supply chain environments. The value of 
this research lies in its contribution to a more generalised understanding of the pathways to improving SCM execution.

This paper has the following structure. First, we present a theoretical framework that underpins the development of the hypotheses and the conceptual model. Then, we outline the methodologies of two empirical studies and provide an analysis of our testing of the conceptual model using variance-based structural equation modelling and importanceperformance analyses. The presentation of the results and subsequent theoretical and practical contributions of this research follows, and finally an outlook on further research based on the main limitations related to the conceptual scope and empirical findings concludes the paper.

\section{Theoretical background}

Supply chains consist of many actors including suppliers, distributors, manufacturers and ultimate customers (Heizer and Render 2014). Therefore, supply chains represent long, complex and interwoven sequences of vertically order-connected firms (Kotzab and Otto 2004). Following Thompson's (1967) idea of long-linked technology, supply chains also represent vertical networks of independent organisations (Håkansson and Ford 2002; Brass et al. 2004; Choi and Wu 2009). By being part of such networks, organisations - and those representing them - aim to maximise efficiencies and synergies, build competencies and acquire resources that they could not acquire on their own (Chetty and Wilson 2003;

Håkansson and Persson 2004; Esper and Defee 2010; Boute, Van Dierdonck, and Vereecke 2011; Alfalla-Luque, Medina-Lopez, and Dey 2013; Alfalla-Luque, Medina-Lopez, and Schrage 2013). According to Simchi-Levi, Kaminsky, and Simchi-Levi (2008), companies that integrate their business processes with suppliers and customers are better able to produce and distribute their products by lowering their system costs while satisfying service-level requirements. 
The management of such vertical networks, or SCM, according to Fettke (2007), refers to three specific inter-organisational flow management areas:

- The management of the flow of goods refers to the harmonisation of the flow of goods between the suppliers' suppliers and the customers' customers.

- The management of the flow of information refers to the demand-driven supply of information to all actors.

- The management of cooperation refers to the integration and synchronisation of business processes within and between organisations.

While one can view the first two areas, the flow of goods and related information, as consisting of technical systems such as material flow and information systems, the third area is a social system or network, as managers in organisations decide whether or not to work with upstream and downstream partners as well as the degree of exchange they will have with these partners (Giannakis and Croom 2004). From a transaction cost theory point of view, supply chains offer a hybrid form of contracting (Williamson 2008), including the setting up of specific norms and standards that reward cooperation-compliant behaviour and sanction counteraction. Autonomous decision makers upstream and downstream in the supply chain settle hybrid contracts, and prior researchers view such contracts as the result of a social negotiation process (Halldorsson et al. 2007).

Supply chains can take the form of emergent networks that are borderless, selforganising and have evolved in a bottom-up fashion from bilateral interactions, while strategic networks or value nets, in contrast, consist of sets of organisations, each having clear roles within the network (Möller and Rajala 2007). Such strategic networks have clear structures, roles and goals that are the result of negotiations, and their management makes them more efficient at creating value for their supply chain partners. The basis of this higher 
efficiency is that the network manager knows the capabilities of the actors responsible for creating value, and can therefore better manage value-creating activities and processes (Möller, Rajala, and Svahn 2005). This requires an understanding of the effects SCM resources have on the performance of the firm and the rest of the supply chain (Cook, Heiser, and Sengupta 2011; Johnson and Templar 2011), and on the firm's long-term competitive advantage (Priem and Swink 2012).

From the resource-based theory of the firm (Penrose 2009) and Grant's (1991) proposals regarding competitive advantage, two drivers of the competitive advantages of networks emerge, namely resources and capabilities. Following Wernerfelt (1984), a resource is anything that might be either a strength or a weakness of a given firm. SCM-related resources are, as Barney (1995) and Penrose (2009) suggest, all financial, physical, human and organisational assets that firms use to develop, manufacture and deliver products, the organisational assets being their SCM-related capabilities. In this context, the understanding of the supply chain is as a bundle of heterogeneous resources and capabilities, and the competitiveness of such vertical networks comes from the ability to exploit and organise heterogeneous resources across firms, and take advantage of the capabilities of supply chain partners as a group. Such an approach requires a complex effort to make use of valuable, rare and difficult-to-imitate resources in order to achieve a sustained competitive advantage (Grant 1991).

Thus, the network and resource-based view provides the theoretical lens that links together management resources, capabilities and the execution of the inter-organisational management of vertical networks. Based on this theory we now develop a conceptual model.

\section{Conceptual model}

Key motives behind the cooperation in inter-organisational networks are to acquire resources, 
reduce uncertainty, enhance legitimacy and attain collective goals (Brass et al. 2004).

Ultimately, the central aim of inter-organisational vertical networks is to increase the chances of firm survival, the performance of individual actors, and their ability to create value for their customers (Lambert, Cooper, and Pagh 1998; Frohlich and Westbrook 2001; Mentzer et al. 2001). Researchers have shown the necessity of considering up- and downstream flows as well as improving relationships in such vertical networks. Beske (2012) points out the dynamic character of the resources that are essential to the up- and downstream organisation of supply chains, which necessitates the ongoing identification of these resources and capabilities.

Within supply chain networks, organisations must provide basic management resources, both internally and in relation to their supply chain partners, in order to develop core capabilities such as the execution of SCM (Droge, Jayaram, and Vickery 2004; AlfallaLuque, Medina-Lopez, and Schrage 2013). Internal SCM resources are those assets that lie within an organisation (Kotzab, Friis, and Busk 2006). In contrast to them, joint (supply chain) management resources are a necessary part of building an inter-organisational network with a supplier or customer (Kotzab et al. 2011). The latter resource type refers to an outcome of what Baraldi, Gressetvold, and Harrison (2012) term resource interaction within networks.

Internal SCM resources comprise human and financial resources as well as 'soft factors' such as mutual organisational understanding, trust and commitment (Mentzer et al. 2001; Olhager 2002; Hsuan Mikkola and Skjøtt-Larsen 2004; Yeung et al. 2009), whereas joint SCM resources refer to long-term relationships, shared visions and goals, shared control systems, joint project groups, trust, information sharing about forecasts and inventory status, product development, leadership, organisational culture, mutual dependency, and profit and risk sharing (Bechtel and Jayaram 1997; Cooper, Lambert, and Pagh 1997; Fawcett and Magnan 2001; Mentzer et al. 2001; Droge, Jayaram, and Vickery 2004; Cousins and Menguc 
2006; Das 2006; Cigolini and Rossi 2008; Palomero and Chalmeta 2012; Alfalla-Luque, Medina-Lopez, and Dey 2013; Dey and Cheffi 2013). Kotzab et al. (2011) argue that the putting in place of internal resources - which they label conditions - is a prerequisite for the existence of joint resources. Our first hypothesis is:

$H_{1}$ : The more internal SCM resources are available in an organisation, the more joint SCM resources are available.

Dimitriadis and Koh (2005) emphasise in their work the importance of the existence of human and IT-specific resources, as well as internal and joint documentation, in a company and its partnering companies, in order to facilitate SCM. These internal and external interfaces and their positive effects on the integration of internal and external functions and processes are supported by the findings of Bruce and Daly (2011). The existence of SCM depends, according to Chapman and Corso (2005), on open communication, knowledge sharing, trust and common goal setting. The implementation of cross-functional teams and the existence of trust and commitment are identified by Chen, Paulraj, and Lado (2004) as critical elements for the internal and external coordination and integration of business processes. Jayaram, Tan, and Nachiappan (2010) refer in their work to the participation in inter-organisational decision making, which requires communication and information-sharing resources as central prerequisites for SCM. Based on the notions of Lambert, GarcíaDastugue, and Croxton (2005), Simchi-Levi, Kaminsky, and Simchi-Levi (2008) and empirical findings from Kotzab et al. (2011), internal and joint SCM resources act as the drivers of SCM execution. Consequently, we hypothesise that: $\mathrm{H}_{2}$ : The more (a) internal/(b) joint SCM resources are available in an organisation, the higher is the level of SCM execution.

The ability to adopt SCM-related processes, understood as processes that interconnect the partners in a supply chain (Croxton et al. 2001), is an elementary capability that drives 
network integration and performance (Lambert, Cooper, and Pagh 1998; Dey and Cheffi 2013). Wilkinson and Young's (2002) and Li et al.'s (2006) view of the need to jointly manage networks and thus inter-organisational processes in order to enhance competitiveness and overall performance supports such a relationship. When looking at the interorganisational SCM processes that directly affect the execution of SCM, the literature (Cooper, Lambert, and Pagh 1997; Croxton et al. 2001; Lambert, García-Dastugue, and Croxton 2005) comes up with eight processes: (1) customer relationship management, that is, the development and maintenance of relationships with customers; (2) customer service management, that is, a single source of customer information and a key point of contact for administering product service agreements; (3) demand management, that is, balancing the customers' requirements with supply capabilities; (4) order fulfilment, that is, all activities necessary to define customer requirements; (5) manufacturing flow management, that is, all activities necessary to obtain, implement and manage manufacturing flexibility and move products through the plants in the supply chain; (6) supplier relationship management, that is, the development and maintenance of relationships with suppliers; (7) product development and commercialisation, that is, the development and market introduction of new products together with suppliers and customers; (8) returns management, that is, all activities with regard to returns, reverse logistics and avoidance.

These processes enable the joint development of resources, which Gadde, Hjelmgren, and Skarp (2012) label an important element of inter-organisational relationships. Kotzab, Friis, and Busk (2006) propose a link between supply chain processes and SCM execution (see also Bechtel and Jayaram 1997; Lambert, Cooper, and Pagh 1998; Mentzer et al. 2001). These closer linkages between processes are intended to result in tighter relationships between network partners and the establishment of joint network management, a requirement for building an effective value or channel net(work) that elevates the competitiveness of the 
network partners involved (Möller, Rajala, and Svahn 2005). Olhager (2002) calls this the necessary mindset of the involved partners that is important for competing successfully in the market. Thus we hypothesise that:

$H_{3}:$ The greater is the firm's capability to adopt SCM-related processes, the higher is the level of SCM execution.

Given the integral role supply chain processes play in the execution of SCM, the capability to adopt processes relies on both the internal and, in particular, the joint supply chain resources in an organisation (Alfalla-Luque, Medina-Lopez, and Schrage 2013; Lambert, García-Dastugue, and Croxton 2005). Cigolini and Rossi (2008) thereby refer to the relation between the performance of the supply chain and the ability to achieve intra- and inter-organisational coordination of the involved business processes and units. This then improves the overall competitiveness of the company. We thus propose a direct association between both internal and joint SCM resources, and the adoption of SCM-related processes: H4: The more (a) internal/(b) joint SCM resources are available in an organisation, the greater is the firm's capability to adopt SCM-related processes.

Our first four hypotheses are linked and suggest a mediating role played by the capability to adopt SCM-related processes. This is in line with the notions of Teller, Kotzab, and Grant (2012), who argue that supply chain processes leverage the use of SCM resources to affect the execution of SCM. Such a proposed mediation is also supported by Baraldi, Gressetvold, and Harrison's (2012) notions on the interaction of resources, and their view on how network partners combine and develop them in order to establish capabilities that further support the management and subsequently the competitiveness of networks. Further, Grant (1991) sees resources as filtered through capabilities in networks, subsequently leading to competitive advantage. Thus, we hypothesise that: 
H5: The capability to adopt SCM-related processes significantly mediates the association between (a) internal / (b) joint SCM resources and the execution of SCM.

The five hypotheses together form the conceptual model, and Figure 1 depicts the relationships between the hypotheses in the form of associations between constructs.

\section{Figure 1 here.}

\section{Methodology}

\subsection{Research design}

The empirical testing of the conceptual model and hypotheses uses data from two surveys that took place in Austria and Denmark. The two samples reflect two comparable supply chain environments based on the World Bank's Logistics Performance Index (LPI) (Arvis et al. 2014). With a LPI of 3.78 and ranked $17^{\text {th }}$, Denmark represents a northern European supply chain environment. Austria represents a central European supply chain environment and has an LPI of 3.65, placing it in $22^{\text {nd }}$ position (Arvis et al. 2014).

The research design - except for the sample selection procedure - was identical in both cases. In both cases, a survey approach was taken, utilising self-administered questionnaires that contained 38 questions reflecting the various dimensions of the constructs in the model, and six questions characterising the respondents and the organisations they represented. A back-translation procedure Behling and Law (2000) helped to ensure the linguistic equivalence of the survey stimuli. Due to a higher implementation level of SCM in large organisations, and arguably the competence of the specialised personnel working there, the bigger organisations in each country became the population of interest. In both cases, the key informants targeted within the organisations were the senior managers responsible for logistics and SCM. In Austria, 790 potential survey participants were identified, representing the biggest organisations in the retail and manufacturing sectors, as per the ÖNACE 
classification. From that population, with our sample selection procedure we targeted 200 organisations at random. In Denmark, the targeted group was all organisations with more than 10 employees and a sales volume of more than 20 million DKK. A popular trade journal in the field of logistics and SCM was the distribution medium of choice. The resulting Danish dataset contained 100 usable responses and the Austrian one 174.

The Danish sample includes respondents representing manufacturing (70\%), service (17\%) and trading (13\%) organisations. In contrast, the Austrian sample contains a smaller share of manufacturing companies (39\%) and a higher share of organisations in the trade sector (29\%). The remainder belong to the service, building and energy sectors. The test for non-response bias made use of early and late respondents, as Armstrong and Overton (1977) and Wagner and Kemmerling (2010) suggest, and no such issues emerged for either dataset.

\subsection{Measures}

Construct measures: The conceptual model relies on the measurement instrument that Kotzab, Friis, and Busk (2006) developed and Kotzab et al. (2011) purified, comprising exploratory factor analyses and tests for reliability and validity. Those authors presented a detailed discussion of the various items standing behind the constructs. All constructs are of a reflective nature, meaning that the indicators represent manifestations of the constructs (Jarvis et al. 2003).

Despite using the same set of measurement items, we revisited the construct labelling proposed by those authors. By carefully examining the items subsumed under the SCM condition constructs, we concluded that they actually represented internal and joint SCM resources. The formulation of Kotzab et al.'s (2011) items behind the construct of 'adoption of SCM' - all of which refer to a rating of how capable a company is at adopting a SCM process - warranted a marginal relabelling to 'capability to adopt SCM-related processes'. Based on the discussion alongside the development of our hypotheses above, and referring to 
the item formulation (see Table 2), we argue that the marginally amended labels provide a better representation of the measures standing behind the construct.

Control variables: We considered two control variable that potentially influence the associations hypothesised above: industry affiliation $\left(c_{1}\right)$, company size $\left(c_{2}\right)$ and country affiliation $\left(c_{3}\right)$ (see Figure 1). Harland (1996) identified that the position of a company in a supply chain (= industry affiliation) affects the management of supply chains and its execution. Given the distribution of industry affiliation in our samples we used a dichotomous scale to measure our first control variable, that is, the companies - represented by our respondents - are either affiliated to the manufacturing industry or to any other industry.

The rationale for including our second control variable is supported by discussion on the different roles, practice and execution of SCM in large as opposed to small organisations, and thus the notion that the size of a company affects the advantages gained from SCM (Arend and Wisner 2005). The company size is operationalised by the number of full-timeequivalent employees.

Our data set includes studies from two comparable and yet different supply chain contexts. By including country affiliation as a control variable we explore whether there is a confounding effect on our model that is related differences between the two subsamples.

\subsection{Analyses}

Variance-based structural equation modelling: To analyse the proposed associations between the four reflective latent constructs, partial least squares (PLS) path modelling proved to be the most appropriate approach (Wold 1975; Lohmueller 1989; Chin 1998; Tenenhaus et al. 2005). The software SmartPLS (Ringle, Wende, and Will 2005) served this purpose. The reason for this choice was the less strict requirements of the PLS procedure in terms of sample size, level of measurement and multinormality (Fornell and Bookstein 1982; Chin and 
Newsted 1999). The structural equation analysis consisted of two parts: (1) the evaluation of the measurement or outer models, that is, the sets of constructs with the observable items standing behind them, and (2) the investigation of the proposed associations between the latent constructs within the structural or inner models.

Importance-Performance Analysis: To make the results of the hypothesis testing more meaningful with respect to the second aim of this paper, that is, identifying the drivers of SCM execution given the current execution level, the next step was to use the results from the PLS path modelling to conduct an importance-performance analysis (IPA). IPA is a widely accepted analytical tool within the area of customer satisfaction research (Johnson and Gustafsson 2000). We followed Johnson and Gustafsson (2000) as well as Teller, Kotzab, and Grant (2012) in setting up the IPA.

The performance index scores determine the level of SCM execution within the organisations for the constructs $\xi_{1}, \xi_{2}$ and $\xi_{3}$, that is, the factors proposed to influence SCM execution. The performance index refers to the (rescaled) mean value of the item ratings, weighted by the relative impact of each item within each factor. The weighting parameter denotes the factor weights, which indicate the relative importance of each indicator $\left(\mathrm{x}_{1 \mathrm{n}}, \mathrm{x}_{2 \mathrm{n}}\right.$, $\left.\mathrm{x}_{3 \mathrm{n}}, \mathrm{y}_{4 \mathrm{n}}\right)$ to the measurement of the respective constructs $\left(\xi_{1,2,3}, \eta_{1}\right)$ (see appendix; Lohmueller 1989; Tenenhaus et al. 2005). The next step was to recode the five-point rating scales into a 100-point scale ( $0=$ lowest possible performance; $100=$ highest possible performance). The step after that was to combine the performance index values with the impact values, that is, the structural or inner weights. Whereas the former set of weights shows the current execution level (high/low performance), the latter set characterises the potential of each construct to change this current state (high/low impact). The final task was to plot the combinations in impact-performance matrices, enabling the identification of focal areas for 
improvement and the discussion of priority setting aimed at changing the SCM execution levels within an organisation.

Construct validity: All $t$-values of the factor loadings proved to be highly significant at $p<0.001$ (see appendix). Almost all loadings exceed or are slightly below the suggested size of 0.70 (Hulland 1999). The internal consistency is also satisfactory for all factors (Cronbach's alpha $(\alpha)>0.70)$, and for all factors the composite reliability $(\rho)$ meets the requirement of being above 0.70 (Fornell and Larcker 1981). The degree of convergent validity proved to be acceptable, with the average variances extracted (AVE) higher than 0.50 (Bagozzi and Yi 1988). With regard to the constructs' discriminant validity, the AVE is larger than the highest of the squared inter-correlations with the other factors in the measurement models (see Table 1). Additionally, all factor loadings on the assigned factor are higher than all loadings, that is, cross-loadings, on the non-assigned factors (Chin 1998). To conclude, all constructs in the model show sufficient validity.

\section{Table 1 here.}

Model robustness test: Next, we evaluated the impact of our three control variables $\left(c_{1}, c_{2}\right.$ and $\left.c_{3}\right)$ on the main associations in our baseline model, i.e. a model estimated based on the Austrian and Danish data (see Figure 1) by following the procedure applied by Robson, Katsikeas, and Bello (2008). The direct impact of $c_{1}$ and $c_{2}$ on the affected constructs $\xi_{2}, \xi_{3}$ and $\eta_{1}$ are all insignificant $(t$-values $<<1.965)$ and very weak $\left(f^{2}\right.$-values $\left.<<0.100\right)$ (see Table 3$)$. When comparing the structural associations as proposed in our hypotheses $\left(\gamma_{21}, \gamma_{11}, \gamma_{12}, \gamma_{31}\right.$, $\left.\gamma_{32}, \gamma_{13}\right)$ by including the control variables in the model or not, we see that the coefficients change insignificantly on the third decimal place and the significances of the associations do not change. These results suggest that the two control variables do not confound the proposed relationships in our conceptual model. Moreover, we can conclude that the structural 
associations are independent of the industry affiliation and company size. Since the two control variables do not have any explanatory power, we trimmed our model and excluded the control variables from the following analysis steps.

Nevertheless, we see significant ( $t$-values $>1.965)$ and medium sized effects $\left(f^{2}\right.$ values 0.125 ) of our country dummy variable $\left(c_{3}\right)$ on all three dependent constructs (see Table 2). When comparing the coefficients with and without our control variable $c_{3}$ and following Keil et al. 's (2000) multi-group comparison approach we see only one significant difference $(p<.05)$ in the associations in our model. The effect between $\xi_{1}$ and $\xi_{3}$, i.e. the structural path $\gamma_{31}$, is significantly stronger the Danish modelling results. Thus we leave $c_{3}$ in our (baseline) model and control for country affiliation. We additionally present the modelling result from both country settings separately and test for moderating effects.

Common method bias: Since the study uses data based on self-reports, another important task was to consider the issue of common method bias (CMB). Here we followed a two-step approach. First we tried to avoid CMB upfront by taking into consideration the notions of Podsakoff et al. (2003, 2012) when designing the questionnaire. Most importantly, we kept the size of the questionnaire to two A4 pages, something that is known to significantly reduce the fatigue effect on respondents. In terms of the structure of the research instrument, there was a clear separation of questions in the questionnaire. Neither the questionnaire nor the pre-notification material revealed the specific purpose of the project, and both assured confidentiality to the respondents.

In a second step, we tested whether common method variance biases our data. In terms of testing for $\mathrm{CMB}$, it must be said that there is no single best method available (Podsakoff, MacKenzie, and Podsakoff 2012). Further, there is a critical debate on which method to use and how significantly (or not) CMB can affect data (for a critical discussion 
see, for example, Richardson, Simmering, and Sturman 2009). We conducted a Harman's one-factor test on both datasets (Podsakoff and Organ 1986). To do so, we conducted exploratory factor analysis (EFA) on our 38 variables using unrotated principal component factor analysis constraining the number of factors to be extracted to one, i.e. one general factor. We see that the one-factor solution accounts for around one third of the total variance. Further we introduced a latent method factor (LMF) and thereby subsumed all indicators under one construct in our model according to Podsakoff et al. (2003). We estimated the model with and without the LMF and compared the results. We found that neither the factor loadings nor the path coefficients are substantially different in value, are all significant $(t$ value $>1.965$ ) and positive. To conclude, the results from both tests suggest that common method variance is not a significant issue in our data, implying that CMB does not harm the interpretation of our results.

Global fit: We also evaluate the overall fit of our conceptual model with the empirical data and calculated the goodness-of-fit criterion according to the notions of Tenenhaus et al. (2005). They propose a global fit measure in the form of the geometric mean of the average communality and the average $r^{2}$. This global fit measure is above the recommended threshold of 0.5 (see Table 3 ). We can thus conclude that there is a satisfactory fit of our conceptual model with the Austrian, Danish and aggregated data of both samples.

\section{Findings}

\subsection{Structural effects}

The evaluation of the structural models follows Chin (1998) by using the coefficients of determination $\left(r^{2}\right)$, the sizes, signs and significances of the single path coefficients $\left(\gamma_{n}\right)$, and the strength of the association (effect size, $f^{2}$ ), as shown in Table 2.

Table 2 here. 
The results from estimating the baseline model using the combined data of the Austrian and Danish data set reveal only significant path coefficients ( $t$-value $>1.965)$. This leads to the acceptance of $\mathrm{H}_{1}, \mathrm{H}_{2 \mathrm{ab}}, \mathrm{H}_{3}$ and $\mathrm{H}_{4 a b}$ (see Table 2). To further analyse the associations, it is necessary to interpret the effect sizes according to the notions of Cohen (1988), using $f^{2}$-values. The $f^{2}$-values suggest that the association between the two resource constructs is substantial $\left(f^{2}>0.350\right)$. The impact of the external SCM resources and the SCMrelated processes on SCM execution is moderate $\left(f^{2} \sim 0.150\right)$. The remaining effects are rather weak $\left(f^{2} \sim 0.020\right)$. When comparing the path coefficients between the two samples we only see - as mentioned above - a moderating effect on the path $\gamma_{31}$ (see Table 2).

In the Austrian sample, the $t$-values of five path coefficients proved to be significant at $p<0.05$ and all coefficients have a positive sign as the hypotheses proposed. Only the internal SCM resources do not significantly affect SCM-related processes. This result confirms $\mathrm{H}_{1}, \mathrm{H}_{2} \mathrm{ab}, \mathrm{H}_{3}$ and $\mathrm{H}_{4 \mathrm{~b}}$. The strongest and most considerable association is found to be between the internal SCM resources and the joint SCM resources. Furthermore, moderate associations are identifiable between the joint SCM resources and the SCM-related processes and, finally, between the processes and SCM. All other associations turned out to be weak.

The Danish sample displays similar results. With respect to the $t$-values of the path coefficients, all are significant at the 5\% level. All path coefficients show a positive sign. This result supports hypotheses $\mathrm{H}_{1}, \mathrm{H}_{2} \mathrm{ab}, \mathrm{H}_{3}$ and $\mathrm{H}_{4 a b}$. Again, the association between the internal and joint SCM resources shows the highest $f^{2}$-value. With the exception of the small effect size between the internal SCM resources and the execution of SCM, all other associations are of a moderate nature.

\subsection{Mediation}

The mediation test related to the construct $\xi_{3}$ followed the four-step procedure of Baron and 
Kenny (1986), and - unlike in the above-described testing of the whole model - estimated the association separately for each set of constructs (see $\mathrm{H}_{3 a}$ and $\mathrm{H}_{3 b}$ ):

- The procedure started (step 1) with a test of the direct association between the two constructs of SCM resources ( $\xi_{1}$ and $\xi_{2}$ ) and SCM execution $\left(\eta_{1}\right)$. Here, we initially neglected the possible mediating effect of $\xi_{3}$. Both constructs show significant associations $\left(p<0.001 ; \xi_{1} \rightarrow \eta_{1}, 0.576 ; \xi_{2} \rightarrow \eta_{1}, 0.613\right)$.

- The next step (2) involved the assessment of the associations between the resource constructs and the mediator. Again, significant results emerged $\left(p<0.001 ; \xi_{1} \rightarrow \xi_{3}, 0.575\right.$; $\left.\xi_{2} \rightarrow \xi_{3}, 0.512\right)$

- The third step was to evaluate whether the proposed mediator $\left(\xi_{3}\right)$ affects the endogenous construct. The results show that the impact is significant $\left(p<0.001 ; \xi_{3} \rightarrow \eta_{1}, 0.466\right)$.

- In the fourth step, we investigated the mediated association between our resource constructs and SCM execution assuming that the direct (unmediated) relationship $\left(\xi_{1,2} \rightarrow \eta_{1}\right)$ was zero. All mediated relationships turned out to be significant $(p<0.001$; $\left.\xi_{1} \rightarrow \xi_{3} \rightarrow \eta_{1}, 0.256 ; \xi_{2} \rightarrow \xi_{3} \rightarrow \eta_{1}, 0.606\right)$. Furthermore, we conducted a Sobel's test (Sobel 1982) and concluded from the highly significant Sobel's $z$ values $\left(p<0.001 ; \xi_{1} \rightarrow \xi_{3} \rightarrow \eta_{1}\right.$, 7.232; $\left.\xi_{2} \rightarrow \xi_{3} \rightarrow \eta_{1}, 7.646\right)$ that the indirect associations were significantly different from zero.

- An additional step in the mediation test was the calculation of the size and strength of the mediating effects using the measure 'variance accounted for' (VAF), drawing upon Shrout and Bolger's (2002) formula. The VAF values for the mediated construct ‘internal SCM resources' are 0.318 and those for 'joint SCM resources' are 0.280 . An interpretation of the coefficients using the notions of Cohen (1988) shows the mediating power of $\xi_{3}$ to be of medium size. 
The significant results in each of the four steps confirm both $\mathrm{H}_{5 a}$ and $\mathrm{H}_{5 b}$. In a final step we investigate whether this finding holds for both country samples. The four step procedure conducted for the two subsamples separately shows the same result, i.e. significant and medium size mediation. Further we tested whether the mediation is moderated by the country affiliation. We compared the total effects - including the direct $\left(\xi_{1,2} \rightarrow \eta_{1}\right)$ and indirect effects $\left(\xi_{1,2} \rightarrow \xi_{3} \rightarrow \eta_{1}\right)$ - from our two resource constructs on SCM execution. By again applying the formula of Keil et al.'s (2000) we see that both total effects in the two country settings are not significantly different from each other $(p>0.05)$. Finally we come to the conclusion that - independent of supply chain context - the capability to adopt SCM-related processes significantly mediates the associations between SCM internal and joint resources, respectively, and SCM execution.

\subsection{Performance improvement areas}

Given the significant impact of our country control variable on our dependent constructs we now present the performance improvement areas for the two supply chain environments separately. The performance index scores, which show the current status of execution, in combination with the impact value, that is, the potential to influence the performance level, identify those internal and joint SCM resources and capabilities $\left(\xi_{1}, \xi_{2}, \xi_{3}\right)$ whose prioritisation would enhance the level of SCM execution. Table 3 shows the performance index (PI) scores for both samples and the specific steps of the calculation. The midpoint of the performance scale, 50, serves as a reference value to assist in the interpretation of the results. To investigate differences in performance levels between the two countries, we compared the PI scores for each factor using independent $t$-tests.

Table 3 here. 
The performance-impact matrix shown in Figure 2 combines the PI and the total execution effect levels (i.e. impact) shown in Table 2; for example, the total impact of internal SCM resources is 0.52 for Austria and 0.68 for Denmark. This matrix identifies the major areas for improvement in both supply chain environments and suggests a division of the plot area into quadrants. As with the PI scores, the midpoint of the performance scale, 50, serves as a reference or split value.

Figure 2 here.

The level of SCM execution in the Austrian sample is below the midpoint ( $\mathrm{PI}_{\eta 1}$, 48.08). This low index value also holds for the index score for the joint $\mathrm{SCM}$ resources $\left(\mathrm{PI}_{\xi 2}\right.$, 47.70). The PI score for the internal SCM resources $\left(\mathrm{PI}_{\xi 1}, 54.18\right)$ is slightly above the reference value, showing that these companies have a fairly high level of internal SCM resources. Nevertheless, the SCM-related processes show the highest result $\left(\mathrm{PI}_{\xi 3}, 64.62\right)$.

Looking at the results for the Danish sample, the SCM execution turns out to be below $0.50\left(\mathrm{PI}_{\eta 1}, 49.76\right)$. When comparing this result with the Austrian execution level we see no significant difference $\left(\mathrm{PI}_{\eta 1}: t_{(272)},-0.550, \mathrm{p}>0.5\right)$. Contrary to the situation for the Austrian sample, the internal SCM resources $\left(\mathrm{PI}_{\xi 1}, 44.68\right)$, as well as the capability to adopt SCM-related processes $\left(\mathrm{PI}_{\xi 3}, 42.18\right)$, are at a lower level than the SCM execution. These differences between the PI scores in the two samples are significant $\left(\mathrm{PI}_{\xi 1}: t_{(272)}, 3.374\right.$, $\left.\mathrm{p}<0.01 ; \mathrm{PI}_{\xi 3}: t_{(272)}, 10.169, \mathrm{p}<.001\right)$. The joint $\mathrm{SCM}$ resources perform a little bit better than the average $\left(\mathrm{PI}_{\xi 2}, 51.98\right)$ and the score is higher but (on average) not significantly different to that for the Austrian sample ( $\left.\mathrm{PI}_{\xi 2}: t_{(272)},-1.653, \mathrm{p}>0.05\right)$.

The results depicted in Figure 2 suggest that, for the two samples, despite the fact that the performance levels of internal SCM resources in Austria and joint SCM resources in Denmark are already relatively high, organisations must maintain them at that level or improve them. The internal SCM resources in the Danish enterprises surveyed represent a 
core area for focused improvement, with considerable potential for enhancement. In Austria, the capability to adopt SCM-related processes does not play such an important role, and the results do not indicate a major concern in this area in terms of making additional investments. In Denmark, the capability to adopt SCM-related processes yields great potential for changing the execution level of SCM due to low impact and performance levels. Similarly, joint SCM resources in Austria have low performance and impact potential, albeit at a somewhat higher level. Hence, in that aspect, there is no focal area for improvement suggested by these results.

\section{Implications and conclusions}

The goal of this research paper has been to identify and evaluate intra- and interorganisational management resources that affect the level of SCM implementation (= SCM execution) in a company. Having integrated internal and external business processes with suppliers and customers, companies produce and distribute their products at a lower cost while satisfying service-level requirements (e.g. Simchi-Levi, Kaminsky, and Simchi-Levi 2008). However, SCM has so far been seen as a way of collaboration that is difficult to implement effectively (Dey and Cheffi 2013). With our chosen structural equation modelling approach we have been able to show theoretically as well as empirically how the intra- and inter-organisational management resources affect the implementation of SCM in a company. We have also identified an underlying hierarchical structure. Furthermore, we wanted to show what initiatives management can take in order to increase the level of SCM execution in their company. We examined this by applying the IPA, calculating the score values from the results of the structural equation modelling. Overall, our empirical research results provide insights for further developing the supply chain integration framework suggested by Alfalla-Luque, Medina-Lopez, and Schrage (2013). The following theoretical and managerial contributions can be derived from our study: 


\subsection{Theoretical implications}

The first main contribution relates to the crucial role of both internal and joint resources in terms of building up capabilities to implement inter-organisational supply chain processes such as joint demand management, manufacturing flow management or product development processes, as well as the overall SCM execution level. This contribution thus supports the work of Alfalla-Luque, Medina-Lopez, and Schrage (2013). The findings also reveal and suggest a heuristic that network partners should follow when trying to improve or enhance the level of network management. The moderating and strong direct effects within the model indicate the following chain or hierarchy of associations: (1) the internal SCM resources directly affect (2) the joint resources. In turn, these joint SCM resources significantly influence (3) the capability to adopt SCM-related processes. Ultimately, SCM-related processes impact on (4) the execution of SCM. This 'association hierarchy' pathway clearly confirms and adds to Boddy, Macbeth, and Wagner's (2000) notions on the drivers of supply chain partnering. This hierarchy is also in line with Grant's (1991) resource-based view on vertical inter-organisational networks, in suggesting that resources support the development of capabilities that then result in the development and maintenance of competitive advantage. Finally, this pathway reflects a way forward in building and establishing strategic vertical value or net(work)s, or quasi-integrated channels (Cai, Yang, and Hu 2009), and thus enhancing the competitiveness of network firms (Möller, Rajala, and Svahn 2005).

This paper also contributes by providing insights into two heterogeneous supply chain network settings that reveal remarkably homogeneous results, underlining the robustness of the conclusions regarding the enabling role of management resources and the mediating role of network capabilities for the management of networks, and finally the core areas for improvement in SCM execution. 
Another main theoretical contribution of our research lies in the fact that it underlines the crucial role internal management resources play relative to the other drivers of SCM execution. This requirement for inner readiness and investment in the internal resources of an organisation in order to elevate the network management execution level confirms Mentzer et al.'s (2001) and Lambert's (2004) conceptual notions, as well as empirically supporting Alfalla-Luque, Medina-Lopez, and Schrage's (2013) Proposition 2 on the need to internally integrate first before implementing external integration.

The final and more generic contribution of this paper is to provide conceptual support for, and empirical proof of, the enabling role of intra- and inter-organisational management resources for inter-organisational or network management. This view of SCM resources supports the resource-based view of inter-organisational networks in general (Håkansson and Ford 2002; Möller and Rajala 2007) and of emergent networks such as supply chains in particular (Faria and Wensley 2002; Droge, Jayaram, and Vickery 2004). Further, this finding supports Wilkinson and Young's (2002) as well as Alfalla-Luque, Medina-Lopez, and Schrage's (2013) recent views on the need - despite the numerous challenges - for the interorganisational management of relationships utilising shared management resources in order to maximise performance and competitiveness in markets. This paper also confirms Baraldi, Gressetvold, and Harrison's (2012) view on the importance of considering the utilisation and management of resources and their interaction when managing vertical networks such as supply chains. The study also shows how these management capabilities, in terms of the ability to adopt inter-organisational processes, leverage the impact of resources, which confirms Lambert, García-Dastugue, and Croxton (2005) and Paulraj, Chen, and Lado (2012). This finding, in line with those of Gadde, Hjelmgren, and Skarp (2012) and Palomero and Chalmeta (2012), calls for the joint development of resources, for example by means of facilitating collaborative processes. 


\subsection{Managerial implications}

The results of our study have direct managerial implications. They provide supply chain decision makers with the necessary insight into which intra- and inter-organisational management resources need to be provided in order for a firm to implement SCM. Being able to manage a supply chain in an optimal manner is essential for the cost-effective utilisation of production capabilities and capacities (Walters 2002). Based on our empirical findings, we provide supply chain decision makers with a pathway to follow for enhancing the level of SCM execution.

The pathway to follow: While other research (e.g. Ho, Au, and Newton 2002) generally presents collaboration as one of the important drivers of SCM execution, our findings offer empirical evidence of a causal chain demonstrating how SCM-specific resources, SCM processes and the execution of SCM are interrelated. This will allow managers to identify the underlying determining factors of SCM execution in their firms. We show that the capability to adopt SCM-related processes depends firstly on the provision of internal SCM resources, and subsequently on the provision of joint SCM resources. Even though the existence of such resources is important for the level of SCM execution, our results have shown that there are also other resources that drive the transformation activities of a firm. Thus, the capability to adopt SCM-related processes generates a leverage effect.

The measures to prioritise: The results of the IPA will assist supply chain managers to identify resource elements to focus on (both inside a company and in potential partners) when leveraging the execution of SCM. These elements are understood as improvement areas that will help to increase the level of execution of SCM. Linking the information given in Figure 2 and Table 3 leads to a list of areas to be prioritised when improving the level of SCM execution as suggested in our pathway to follow. 
In both supply chain settings we identified internal SCM resources as the main driver of execution and joint SCM resources as an additional driver in the Danish setting (see Figure 2). The impact value of each of these individual SCM resources (see Table 3) allows us to rank their relative importance. There we can see that guidelines on information exchange between supply chain partners $\left(i_{x 17}, .10\right)$ as well as the internal evaluation of supply chain processes $\left(i_{x 113}, .10\right)$ were identified as the indicators with the highest impact/importance in the Austrian setting. In the Danish supply chain setting, we can see that the indicators with the highest impact scores refer to the capability of the companies' IT systems to process data from other supply chain members (internal resources, $i_{x 16}, .12$ ) and to the exchange of information regarding stock levels with other SC members (external resources, $i_{x 210}, .15$ ). Improving these areas in the respective supply chain setting will thus lead to a higher level of SCM execution. Further details on which internal and joint SCM resource to focus can be retrieved from Table 3.

Overall, our two independent samples show similar levels of supply chain execution. However different strategies need to be applied in each in order to enhance those levels. Our studies can support developing such strategies by having a more in-depth look at our results on a concrete indicator as well as on an abstract construct level.

\section{Limitations and further research}

As with every empirical study, ours has limitations that call for further research. One is the country- and industry-specific context in which the fieldwork was carried out. However, the research design focused on reducing that problem by drawing on two datasets constructed in different SCM environments. Nevertheless, future applications should test this model in other countries, starting with other European ones, in order to validate it across other markets. 
The study results reflect the views of experts representing large organisations. The basis for this choice of core informant was the belief that the execution of SCM is more of an issue for this type of supply chain partner. Further research should extend this view towards smaller organisations and test the model with respect to their role in supply chain partnerships.

The findings reflect an aggregated view, comprising the responses from diverse kinds of supply chain partners. They therefore neglect, for example, the heterogeneity of responses. One of the next steps will be to consider the moderators that influence the associations. Such moderators could include affiliations to particular supply chain stages and industries, or the size of supply chain partners.

Furthermore, the resource-based view has some links to the relational view (Dyer and Singh 1998), which shows how interconnected organisations are able to create sustainable competitive advantage. Following these notions, Lavie's (2006) idea of shared resources as a mix of internal and joint network resources could inform the notions of internal and joint SCM resources that appear in this paper.

\section{Appendix}

Appendix here. 


\section{References}

Alfalla-Luque, R., C. Medina-Lopez, and P. K. Dey. 2013. "Supply chain integration framework using literature review." Production Planning \& Control 24 (8-9): 800817.

Alfalla-Luque, R., C. Medina-Lopez, and H. Schrage. 2013. "A study of supply chain integration in the aeronautics sector." Production Planning \& Control 24 (8-9): 769-784.

Arend, R. J. and J. D. Wisner. 2005. "Small business and supply chain management: Is there a fit?" Journal of Business Venturing 20 (3): 403-436.

Armstrong, J. S. and T. S. Overton. 1977. "Estimating nonresponse bias in mail surveys." Journal of Marketing Research 14 (3): 396-402.

Arvis, J., M. A. Mustra, L. Ojala, B. Shepherd, and D. Saslavsky. 2014. The Logistics Performance Index and its Indicators. Washington: The International Bank for Reconstruction and Development/The World Bank.

Bagozzi, R. P. and Y. Yi. 1988. "On the evaluation of structural equation models." 16 (1): 74-94.

Baraldi, E., E. Gressetvold, and D. Harrison. 2012. "Resource interaction in interorganizational networks: Foundations, comparison, and a research agenda." Journal of Business Research 65 (2): 266-276.

Barney, J. B. 1995. "Looking inside for competitive advantage." Academy of Management Executive 9 (4): 49-61.

Barney, J. B. 2012. "Purchasing, supply chain management and sustained competitive advantage: The relevance of resource-based theory." Journal of Supply Chain Management 48 (2): 3-6.

Baron, R. M. and D. A. Kenny. 1986. "The moderator-mediator variable distinction in social psychological research: Conceptual, strategic, and statistical considerations." Journal of Personality and Social Psychology 51 (6): 1173-1182.

Bechtel, C. and J. Jayaram. 1997. "Supply chain management: A strategic perspective." 8 (1): 15-34.

Behling, O. and K. S. Law. 2000. Translating Questionnaires and Other Research Instruments: Problems and Solutions. Thousand Oaks, CA: Sage.

Beske, P. 2012. "Dynamic capabilities and sustainable supply chain management." International Journal of Physical Distribution \& Logistics Management 42 (4): 372-387. 
Boddy, D., D. Macbeth, and B. Wagner. 2000. "Implementing collaboration between organizations: An empirical study of supply chain partnering." Journal of Management Studies 37 (7): 1003-1018.

Boute, R., R. Van Dierdonck, and A. Vereecke. 2011. "Organising for supply chain management." International Journal of Logistics: Research \& Applications 14 (5): 297-315.

Brass, D. J., J. Galaskiewicz, H. R. Greve, and W. Tsai. 2004. "Taking stock of networks and organizations: A multilevel perspective." Academy of Management Journal 47 (6): 795-817.

Bruce, M. and L. Daly. 2011. "Adding value: Challenges for UK apparel supply chain management - a review." Production Planning \& Control 22 (3): 210-220.

Cai, S., Z. Yang, and Z. Hu. 2009. "Exploring the governance mechanisms of quasiintegration in buyer-supplier relationships." Journal of Business Research 62 (6): 660-666.

Chapman, R. L. and M. Corso. 2005. "From continuous improvement to collaborative innovation: The next challenge in supply chain management." Production Planning \& Control 16 (4): 339-344.

Chen, I. J., A. Paulraj, and A. A. Lado. 2004. "Strategic purchasing, supply management, and firm performance." Journal of Operations Management 22 (5): 505-523.

Chetty, S. K. and H. I. M. Wilson. 2003. "Collaborating with competitors to acquire resources." International Business Review 12 (1): 61-81.

Chin, W. W. 1998. "The Partial Least Squares Approach to Structural Equation Modelling." In Modern Methods for Business Research, edited by Marcoulides, G. A., 295-336. Hillsdale, NJ: Lawrence Erlbaum Associates.

Chin, W. W. and P. R. Newsted. 1999. "Structural Equation Modelling: Analysis with Small Samples using Partial Least Squares." In Statistical Strategies for Small Sample Research, edited by Hoyle, R. H., 307-341. Thousand Oaks, CA: Sage.

Choi, T. Y. and Z. Wu. 2009. "Triads in supply networks: Theorizing buyer-suppliersupplier relationships." Journal of Supply Chain Management 45 (1): 8-25.

Cigolini, R. and T. Rossi. 2008. "Evaluating supply chain integration: A case study using fuzzy logic." Production Planning \& Control 19 (3): 242-255.

Cohen, J. 1988. Statistical Power Analysis for the Behavioral Sciences. Hillsdale, NJ: Lawrence Erlbaum Associates.

Cook, L. S., D. R. Heiser, and K. Sengupta. 2011. "The moderating effect of supply chain role on the relationship between supply chain practices and performance. an 
empirical analysis." International Journal of Physical Distribution \& Logistics Management 41 (2): 104-134.

Cooper, M. C. and L. M. Ellram. 1993. "Characteristics of supply chain management and the implications for purchasing and logistics strategy." International Journal of Logistics Management 4 (2): 13-24.

Cooper, M. C., D. M. Lambert, and J. D. Pagh. 1997. "Supply chain management: More than a new name for logistics." International Journal of Logistics Management 8 (1): 1-14.

Corbett, C. J., J. D. Blackburn, and L. N. van Wassenhove. 1999. "Partnerships to improve supply chains." Sloan Management Review 40 (4): 71-82.

Cousins, P. D. and B. Menguc. 2006. "The implications of socialization and integration in supply chain management." Journal of Operations Management 24 (5): 604-620.

Croxton, K. L., S. J. García-Dastugue, D. M. Lambert, and D. S. Rogers. 2001. "The supply chain management processes." International Journal of Logistics Management 12 (2): 13-36.

Das, T. K. 2006. "Strategic alliance temporalities and partner opportunism." British Journal of Management 17 (1): 1-21.

Dey, P. K. and W. Cheffi. 2013. "Managing supply chain integration: Contemporary approaches and scope for further research." Production Planning \& Control 24 (89): 653-657.

Dierickx, I. and K. Cool. 1989. "Asset stock accumulation and sustainability of competitive advantage." Management Science 35 (12): 1504-1511.

Dimitriadis, N. I. and S. C. L. Koh. 2005. "Information flow and supply chain management in local production networks: The role of people and information systems." Production Planning \& Control 16 (6): 545-554.

Droge, C., J. Jayaram, and S. K. Vickery. 2004. "The effects of internal versus external integration practices on time-based performance and overall firm performance." Journal of Operations Management 22 (6): 557-573.

Dyer, J. H. and H. Singh. 1998. "The relational view: Cooperative strategy and sources of interorganizational competitive advantage." Academy of Management Review 23 (4): 660-679.

Esper, T. L. and C. C. Defee. 2010. "A framework of supply chain orientation." International Journal of Logistics Management 21 (2): 161-179.

Faria, A. and R. Wensley. 2002. "In search of 'interfirm management' in supply chains: Recognizing contradictions of language and power of listening." Journal of Business Research 55 (7): 603-610. 
Fawcett, S. E. and G. M. Magnan. 2001. Achieving World-Class Supply Chain Alignment: Benefits, Barriers, and Bridges. Phoenix, AZ: National Association of Purchasing Management.

Fettke, P. 2007. "Supply chain management: Stand der empirischen forschung." Zeitschrift Für Betriebswirtschaft 77 (4): 417-461.

Fornell, C. and D. F. Larcker. 1981. "Evaluating structural equation models with unobservable variables and measurement error." Journal of Marketing Research 18 (1): 39-40.

Fornell, C. and F. L. Bookstein. 1982. "Two structural equation models: LISREL and PLS applied to consumer exit-voice theory." Journal of Marketing Research 19 (4): 440-452.

Frohlich, M. T. and R. Westbrook. 2001. "Arcs of integration: An international study of supply chain strategies." Journal of Operations Management 19 (2): 185-200.

Gadde, L., D. Hjelmgren, and F. Skarp. 2012. "Interactive resource development in new business relationships." Journal of Business Research 65 (2): 210-217.

Giannakis, M. and S. R. Croom. 2004. "Toward the development of a supply chain management paradigm: A conceptual framework." Journal of Supply Chain Management 40 (2): 27-37.

Grant, R. M. 1991. "The resource-based theory of competitive advantage: Implications for strategy formulation." California Management Review 33 (3): 114-135.

Håkansson, H. and G. Persson. 2004. "Supply chain management: The logic of supply chains and networks." International Journal of Logistics Management 15 (1): 1126.

Håkansson, H. and D. Ford. 2002. "How should companies interact in business networks?" Journal of Business Research 55 (2): 133-139.

Halldorsson, A., H. Kotzab, J. H. Mikkola, and T. Skjøtt-Larsen. 2007. "Complementary theories to supply chain management." Supply Chain Management 12 (4): 284-296.

Harland, C. M. 1996. "Supply chain management: Relationships, chains and networks." British Journal of Management 7 (SI): S63-S80.

Heikkilä, J. 2002. "From supply to demand chain management: Efficiency and customer satisfaction." Journal of Operations Management 20 (6): 747-767.

Heizer, J. H. and B. Render. 2014. Operations Management: Sustainability and Supply Chain Management. Boston (MA): Pearson. 
Ho, D. C. K., K. F. Au, and E. Newton. 2002. "Empirical research on supply chain management: A critical review and recommendations." International Journal of Production Research 40 (17): 4415-4430.

Hsuan Mikkola, J. and T. Skjøtt-Larsen. 2004. "Supply-chain integration: Implications for mass customization, modularization and postponement strategies." Production Planning \& Control 15 (4): 352-361.

Hulland, J. 1999. "Use of partial least squares (PLS) in strategic management research: A review of four recent studies." Strategic Management Journal 20 (2): 195-204.

Ivanov, D. and B. Sokolov. 2010. Adaptive Supply Chain Management. London: Springer.

Jarvis, C. B., S. B. Mackenzie, P. M. Podsakoff, D. G. Mick, and W. O. Bearden. 2003. "A critical review of construct indicators and measurement model misspecification in marketing and consumer research." Journal of Consumer Research 30 (2): 199218.

Jayaram, J., K. Tan, and S. P. Nachiappan. 2010. "Examining the interrelationships between supply chain integration scope and supply chain management efforts." International Journal of Production Research 48 (22): 6837-6857.

Jin, Y., A. M. Fawcett, and S. E. Fawcett. 2013. "Awareness is not enough. commitment and performance implications of supply chain integration." International Journal of Physical Distribution \& Logistics Management 43 (3): 205-230.

Johnson, M. and S. Templar. 2011. "The relationships between supply chain and firm performance. the development and testing of a unified proxy." International Journal of Physical Distribution \& Logistics Management 41 (2): 88-103.

Johnson, M. D. and A. Gustafsson. 2000. Improving Customer Satisfaction, Loyalty and Profit. San Francisco: Jossey-Bass.

Keil, M., B. C. Y. Tan, K. Wei, T. Saarinen, V. Tuunainen, and A. Wassenaar. 2000. "A cross-cultural study on escalation of commitment behavior in software projects." MIS Quarterly 24 (2): 299-325.

Kotzab, H. and A. Otto. 2004. "General process-oriented management principles to manage supply chains: Theoretical identification and discussion." Business Process Management Journal 10 (3): 336-349.

Kotzab, H., A. Friis, and T. Busk. 2006. "The implementation of supply chain management within organizations: Construct, measurement and explorative empirical discussion." Die Unternehmung 60 (2): 89-104.

Kotzab, H., C. Teller, D. B. Grant, and L. Sparks. 2011. "Antecedents for the adoption and execution of supply chain management." Supply Chain Management: An International Journal 16 (4): 231-245. 
Lambert, D. M., M. C. Cooper, and J. D. Pagh. 1998. "Supply chain management: Implementation issues and research opportunities." 9 (2): 1-19.

Lambert, D. M. 2004. "The eight essential supply chain management processes." Supply Chain Management Review 8 (6): 18-26.

Lambert, D. M., S. J. García-Dastugue, and K. L. Croxton. 2005. "An evaluation of process-oriented supply chain management frameworks." Journal of Business Logistics 26 (1): 25-51.

Lavie, D. 2006. "The competitive advantage of interconnected firms: An extension of the resource-based view." Academy of Management Review 31 (3): 638-658.

Li, S., B. Ragu-Nathan, T. Ragu-Nathan, and S. Subba Rao. 2006. "The impact of supply chain management practices on competitive advantage and organizational performance." Omega 34 (2): 107-124.

Lohmueller, J. 1989. Latent Variable Path Modeling with Partial Least Squares. Heidelberg: Physica.

Mentzer, J. T., W. DeWitt, J. S. Keebler, S. Min, N. W. Nix, C. D. Smith, and Z. G. Zacharia. 2001. "Defining supply chain management." Journal of Business Logistics 22 (2): 1-25.

Möller, K. and A. Rajala. 2007. "Rise of strategic nets - new modes of value creation." Industrial Marketing Management 36 (7): 895-908.

Möller, K., A. Rajala, and S. Svahn. 2005. "Strategic business nets-their type and management." Journal of Business Research 58 (9): 1274-1284.

Narasimhan, R. and A. Das. 2001. "The impact of purchasing integration and practices on manufacturing performance." Journal of Operations Management 19 (5): 593609.

Nelson, R. D. 2002. "John deere optimizes operations with supply management efforts." Journal of Organizational Excellence 21 (2): 3-11.

Olhager, J. 2002. "Supply chain management: A just-in-time perspective." Production Planning \& Control 13 (8): 681-687.

Palomero, S. and R. Chalmeta. 2012. "A guide for supply chain integration in SMEs." Production Planning \& Control forthcoming.

Paulraj, A., I. J. Chen, and A. A. Lado. 2012. "An empirical taxonomy of supply chain management practices." Journal of Business Logistics 33 (3): 227-244.

Penrose, E. 2009. The Theory of the Growth of the Firm. Oxford: Oxford University Press. 
Podsakoff, P. M. and D. W. Organ. 1986. "Self-reports in organizational research: Problems and prospects." Journal of Management 12 (4): 531.

Podsakoff, P. M., S. B. MacKenzie, Jeong-Yeon Lee, and N. P. Podsakoff. 2003. "Common method biases in behavioral research: A critical review of the literature and recommended remedies." Journal of Applied Psychology 88 (5): 879-903.

Podsakoff, P. M., S. B. MacKenzie, and N. P. Podsakoff. 2012. "Sources of method bias in social science research and recommendations on how to control it." Annual Review of Psychology 63 (1): 539-569.

Priem, R. L. and M. Swink. 2012. "A demand-side perspective on supply chain management." Journal of Supply Chain Management 48 (2): 7-13.

Richardson, H. A., M. J. Simmering, and M. C. Sturman. 2009. "A tale of three perspectives: Examining post hoc statistical techniques for detection and correction of common method variance." Organizational Research Methods 12 (4): 762-800.

Ringle, C. M., S. Wende, and A. Will. 2005. SmartPLS 2.0 (Beta), Www.Smartpls.De. Hamburg: University of Hamburg.

Robson, M. J., C. S. Katsikeas, and D. C. Bello. 2008. "Drivers and performance outcomes of trust in international strategic alliances: The role of organizational complexity." Organization Science 19 (4): 647-665.

Schnetzler, M. J. and P. Schönsleben. 2007. "The contribution and role of information management in supply chains: A decomposition-based approach." Production Planning \& Control 18 (6): 497-513.

Shrout, P. E. and N. Bolger. 2002. "Mediation in experimental and nonexperimental studies: New procedures and recommendations." Psychological Methods 7 (2): 422-445.

Simchi-Levi, D., P. Kaminsky, and E. Simchi-Levi. 2008. Designing and Managing the Supply Chain: Concepts, Strategies, and Case Studies. Boston: Mcgraw-Hill.

Sobel, M. E. 1982. "Asymptotic Intervals for Indirect Effects in Structural Equations Models." In Sociological Methodology, edited by Leinhart, S., 290-312. San Francisco: Jossey-Bass.

Stock, J. R. and S. L. Boyer. 2009. "Developing a consensus definition of supply chain management: A qualitative study." International Journal of Physical Distribution \& Logistics Management 39 (8): 690-711.

Tarn, J. M., D. C. Yen, and M. Beaumont. 2002. "Exploring the rationales for ERP and SCM integration." Industrial Management \& Data Systems 102 (1): 26.

Teller, C., H. Kotzab, and D. B. Grant. 2012. "Improving the execution of supply chain management in organizations." International Journal of Production Economics 140 (2): 713-720. 
Tenenhaus, M., V. E. Vinzi, Y. M. Chatelin, and C. Lauro. 2005. "PLS path modeling." Computational Statistics \& Data Analysis 48 (1): 159-205.

Thompson, J. D. 1967. Organizations in Action. New York: McGraw Hill.

Wagner, S. M. and R. Kemmerling. 2010. "Handling nonresponse in logistics research." Journal of Business Logistics 31 (2): 357-381.

Walters, D. 2002. Operations Strategy. New York: Palgrave Macmillan.

Wernerfelt, B. 1984. "A resource-based view of the firm." Strategic Management Journal 5 (2): 171-180.

Wilkinson, I. and L. Young. 2002. "On cooperating firms, relations and networks." Journal of Business Research 55 (2): 123-132.

Williamson, O. E. 2008. "Outsourcing: Transaction cost economics and supply chain management." Journal of Supply Chain Management 44 (2): 5-16.

Wold, H. 1975. "Path Models with Latent Variables: The NIPALS Approach." In Quantitative Sociology: International Perspectives on Mathematical and Statistical Modeling, edited by Blalock, H. M., A. Aganbegian, F. M. Borodkin, R. Boudon and V. Capecchi, 307-357. New York: Academic Press.

Yeung, J. H. Y., W. Selen, M. Zhang, and B. Huo. 2009. "The effects of trust and coercive power on supplier integration." International Journal of Production Economics 120 (1): 66-78. 
Figure 1. Structural model

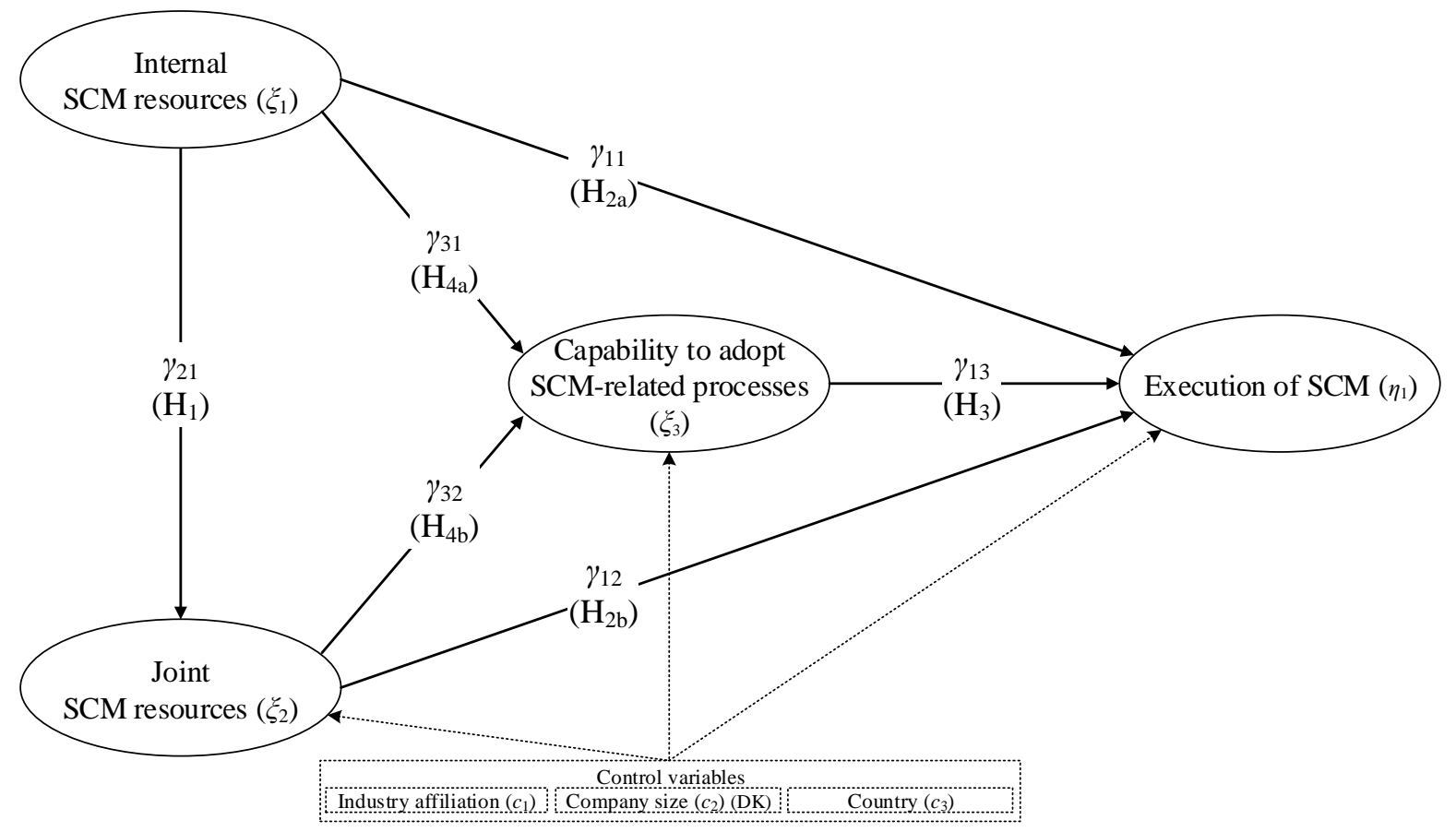

Notes: SCM, Supply Chain Management; $\mathrm{H}_{5 \mathrm{a}}, \xi_{1} \rightarrow \xi_{3} \rightarrow \eta_{1} ; \mathrm{H}_{5 \mathrm{~b}}, \xi_{2} \rightarrow \xi_{3} \rightarrow \eta_{1}$; 
Figure 2. Performance-impact matrix

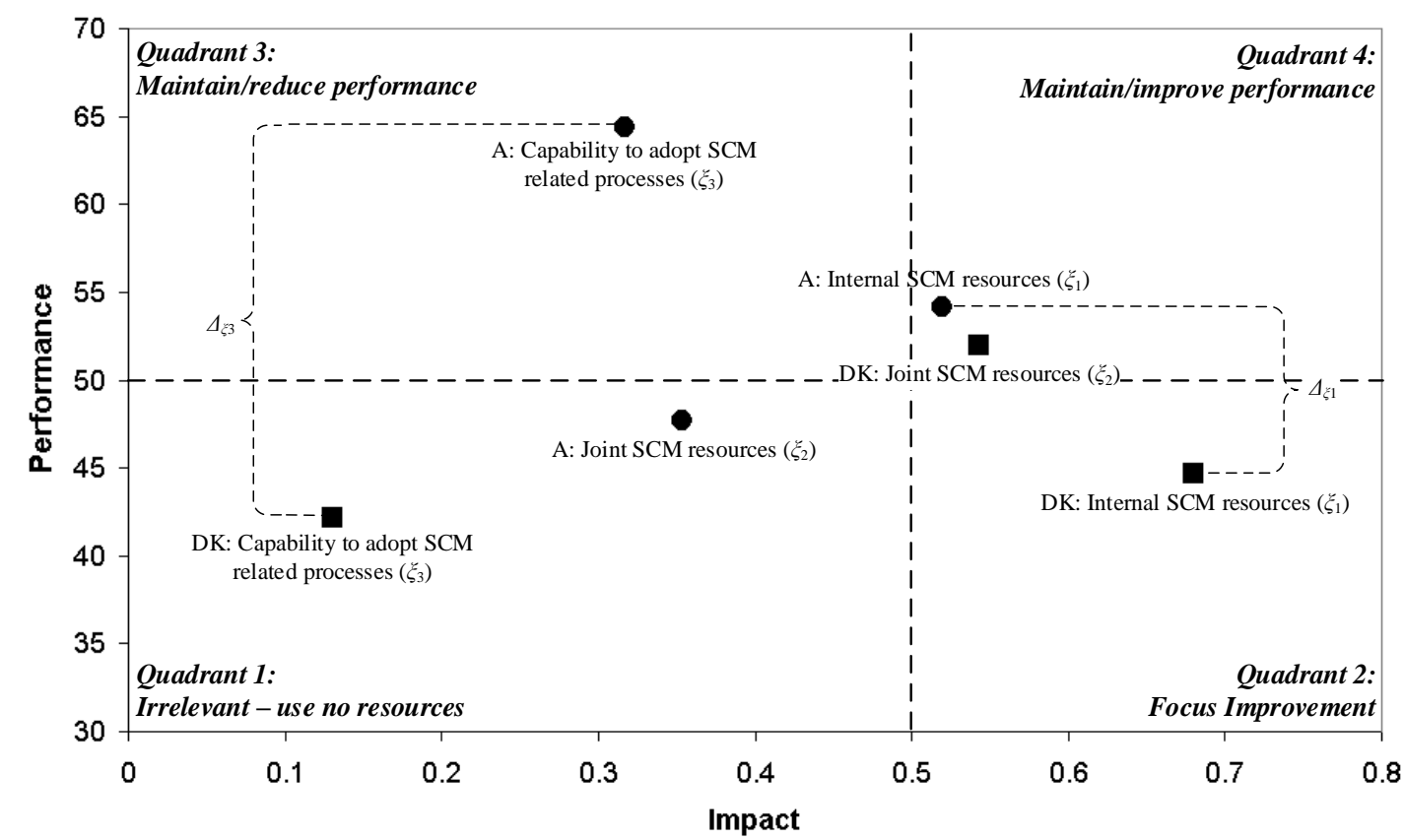


Table 1. Convergent validity, composite reliability and discriminant validity measures

\begin{tabular}{|c|c|c|c|c|c|c|c|c|c|}
\hline $\begin{array}{l}\text { Const } \\
\text { ructs }\end{array}$ & $\rho$ & $\alpha$ & $\xi_{1}$ & $\xi_{2}$ & $\xi_{3}$ & $\eta_{1}$ & $c_{1}$ & $c_{2}$ & $c_{3}$ \\
\hline$\xi_{1}$ & .982 & .932 & $(.813)$ & & & & & & \\
\hline$\xi_{2}$ & .957 & .906 & .545 & $(.622)$ & & & & & \\
\hline$\xi_{3}$ & .940 & .834 & .256 & .099 & $(.675)$ & & & & \\
\hline$\eta_{1}$ & .959 & .750 & .309 & .369 & .130 & $(.888)$ & & & \\
\hline$c_{1}$ & - & - & .001 & .007 & .004 & .001 & $(-)$ & & \\
\hline$c_{2}$ & - & - & .003 & .000 & .024 & .000 & .004 & $(-)$ & \\
\hline$c_{3}$ & - & - & .047 & .007 & .423 & .001 & .020 & .080 & $(-)$ \\
\hline
\end{tabular}

Note: Average variance extracted values (AVE) are presented on the diagonal; squared correlation matrix for latent constructs shown below the diagonal; control $\left(c_{1}, \mathrm{c}_{2}, \mathrm{c}_{3}\right)$ variables are single items constructs; $\alpha$, Cronbach's alpha; $\rho$, composite reliability; $\xi_{1}$, internal SCM resources; $\xi_{2}$, joint SCM resources; $\xi_{3}$, capability to adopt SCM-related processes; $\eta_{1}$, execution of SCM; 
Table 2. Structural model results

\begin{tabular}{|c|c|c|c|c|c|c|c|}
\hline 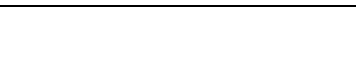 & Baseline model & & Austria & & Denmark & & \\
\hline Direct effects & Coefficient & $f^{2}$-value & Coefficient & $f^{2}$-value & Coefficient & $f^{2}$-value & $\Delta$ \\
\hline$\xi_{1} \rightarrow \eta_{1}\left(\gamma_{11}\right)$ & $.203^{* *}$ & .026 & $.218^{*}$ & .027 & $.221^{*}$ & .044 & n.s. \\
\hline$\xi_{3} \rightarrow \eta_{1}\left(\gamma_{13}\right)$ & $.326^{* * *}$ & .077 & $.317^{* * *}$ & .123 & $.130^{*}$ & .087 & n.s. \\
\hline$\xi_{1} \rightarrow \xi_{3}\left(\gamma_{31}\right)$ & $.222^{* * *}$ & .035 & $.055^{\text {n.s. }}$ & .004 & $.523^{* * *}$ & .273 & $* *$ \\
\hline$\xi_{1} \rightarrow \xi_{2}\left(\gamma_{21}\right)$ & $.794^{* * * *}$ & $>>35$ & $.806^{* * * *}$ & $\gg .35$ & $.719^{* * * *}$ & $\gg .35$ & n.s. \\
\hline \multicolumn{8}{|l|}{ Total effects } \\
\hline$\xi_{1} \rightarrow \eta_{1}\left(\mathrm{Med}, \xi_{2}, \xi_{3}\right)$ & $.592^{* * *}$ & - & $.408^{* * *}$ & - & $.680^{* * * *}$ & - & n.s. \\
\hline$\xi_{1} \rightarrow \xi_{3}\left(\mathrm{Med}, \xi_{2}\right)$ & $.382^{* * *}$ & - & $.524^{* * *}$ & - & $.709^{* * *}$ & - & $* *$ \\
\hline
\end{tabular}

Note: $t$-values calculated by applying a bootstrapping procedure with 1,000 sub-samples (Chin, 1998); multi group analysis conducted based on the formula of Keil et al. (2000); $r^{2}$-values (baseline model/Austria/Denmark): $r^{2}{ }_{(\xi 2)}=.607 / .517 / .650 ; r^{2}{ }_{(\xi 3)}=.578 / .535 / .232$;

$r^{2}(\eta 1)=.443 / .613 / .391$; effects of controls on dependent constructs $\left(c_{1} / c_{2} / c_{3}\right): c_{\mathrm{n}} \rightarrow \xi_{2}, .025^{\text {n.s. }} / .023^{\text {n.s. }} / .256^{* * * *} ; c_{\mathrm{n}} \rightarrow \xi_{3}, .008^{\text {n.s. }} / .023^{\text {n.s. }} /-.618^{* * * *}$;

$c_{\mathrm{n}} \rightarrow \eta_{1},-.014^{\text {n.s. }} /-.037^{\text {n.s. }} / .265^{* * *}$; goodness of fit (baseline model/Austria/Denmark), .619/.549/.586;

Caption: $\xi_{1}$, Internal SCM resources; $\xi_{2}$, joint SCM resources; $\xi_{3}$, capability to adopt SCM-related processes; $\eta_{1}$, execution of SCM; $f^{2}$-values, effect size; $\Delta$, significant difference between coefficients (Austria vs. Denmark); n.s., $t_{(999)}<1.965, \mathrm{p}>0.05$; *, $t_{(999)}>1.965, \mathrm{p}<0.05$; **, $t_{(999)}>$ $2.586, \mathrm{p}<0.01 ; * * *, t_{(999)}>3.31, \mathrm{p}<0.001$; 
Table 3. Level of SCM execution in Danish and Austrian organisations

\begin{tabular}{|c|c|c|c|c|c|c|c|c|c|c|c|c|c|c|}
\hline \multirow{2}{*}{$\begin{array}{c}\text { [Construct] } \\
\text { Item }\left(a_{\mathrm{n}}\right)\end{array}$} & \multicolumn{2}{|c|}{$\mu$} & \multicolumn{2}{|c|}{$\mu_{\text {rescaled }}$} & \multicolumn{2}{|c|}{$\begin{array}{c}\text { Impact }\left(i_{\mathrm{n}}\right) \\
\text { (factor weights) }\end{array}$} & \multicolumn{2}{|c|}{$\begin{array}{c}\text { Sum of factor } \\
\text { weights }\end{array}$} & \multicolumn{2}{|c|}{ Relative impact } & \multicolumn{2}{|c|}{$\begin{array}{c}\text { Weighted PI } \\
\text { per item }\end{array}$} & \multicolumn{2}{|c|}{$\begin{array}{c}\text { Total PI per } \\
\text { construct }\end{array}$} \\
\hline & A & DK & A & DK & $\mathrm{A}$ & DK & A & DK & $\mathrm{A}$ & DK & A & DK & $\mathrm{A}$ & DK \\
\hline$x_{11}$ & 3.04 & 2.86 & 50.96 & 46.57 & .08 & .11 & & & .08 & .09 & 3.95 & 4.31 & & \\
\hline$x_{12}$ & 2.87 & 2.89 & 46.69 & 47.25 & .08 & .10 & & & .08 & .08 & 3.62 & 4.01 & & \\
\hline$x_{13}$ & 3.39 & 2.76 & 59.69 & 44.11 & .08 & .10 & & & .08 & .09 & 4.52 & 3.86 & & \\
\hline$x_{14}$ & 3.13 & 2.96 & 53.15 & 49.12 & .09 & .10 & & & .08 & .08 & 4.47 & 4.05 & & \\
\hline$x_{15}$ & 3.40 & 3.11 & 60.04 & 52.73 & .09 & .08 & & & .08 & .07 & 4.88 & 3.59 & & \\
\hline$x_{16}$ & 3.12 & 2.75 & 53.00 & 43.85 & .09 & .12 & & & .08 & .10 & 4.21 & 4.28 & & \\
\hline$x_{17}$ & 2.83 & 2.95 & 45.77 & 48.83 & .10 & .10 & 1.08 & 1.19 & .09 & .08 & 4.06 & 3.98 & 54.18 & 44.68 \\
\hline$x_{18}$ & 2.92 & 2.81 & 48.03 & 45.30 & .09 & .09 & & & .08 & .07 & 3.95 & 3.28 & & \\
\hline$x_{19}$ & 3.26 & 2.39 & 56.56 & 34.75 & .09 & .09 & & & .08 & .08 & 4.75 & 2.72 & & \\
\hline$x_{110}$ & 3.49 & 2.58 & 62.37 & 39.47 & .06 & .08 & & & .05 & .07 & 3.40 & 2.59 & & \\
\hline$x_{111}$ & 3.36 & 2.67 & 59.04 & 41.87 & .08 & .08 & & & .08 & .07 & 4.52 & 2.75 & & \\
\hline$x_{112}$ & 4.01 & 2.31 & 75.23 & 32.75 & .05 & .08 & & & .05 & .06 & 3.68 & 2.09 & & \\
\hline$x_{113}$ & 2.87 & 3.13 & 46.64 & 53.17 & .10 & .07 & & & .09 & .06 & 4.18 & 3.17 & & \\
\hline
\end{tabular}




\begin{tabular}{|c|c|c|c|c|c|c|c|c|c|c|c|c|c|c|}
\hline $\begin{array}{c}\text { [Construct] } \\
\text { Item }\left(a_{n}\right)\end{array}$ & & $l$ & & & $\begin{array}{r}\text { Im } \\
\text { (factc }\end{array}$ & $\begin{array}{l}\left(i_{\mathrm{n}}\right) \\
\text { eights }\end{array}$ & $\begin{array}{r}\text { Sum } \\
\text { we }\end{array}$ & $\begin{array}{l}\text { factor } \\
\text { ats }\end{array}$ & Relat & mpact & $\begin{array}{r}\mathrm{We} \\
\mathrm{p}\end{array}$ & $\begin{array}{l}\text { ed PI } \\
\text { em }\end{array}$ & $\begin{array}{r}\text { Total } \\
\text { con }\end{array}$ & $\begin{array}{l}\text { I per } \\
\text { ruct }\end{array}$ \\
\hline$\left[\xi_{2}\right]$ & A & DK & A & $\overline{D K}$ & $\mathrm{~A}$ & DK & A & DK & A & DK & $\mathrm{A}$ & DK & A & DK \\
\hline$x_{21}$ & 2.86 & 3.47 & 46.56 & 61.78 & .11 & .11 & \multirow{14}{*}{1.16} & \multirow{14}{*}{1.38} & .09 & .08 & 4.27 & 4.76 & \multirow{14}{*}{47.70} & \multirow{14}{*}{51.98} \\
\hline$x_{22}$ & 2.95 & 3.31 & 48.77 & 57.81 & .10 & .14 & & & .09 & .10 & 4.35 & 5.79 & & \\
\hline$x_{23}$ & 2.55 & 3.09 & 38.79 & 52.27 & .11 & .13 & & & .10 & .09 & 3.73 & 4.74 & & \\
\hline$x_{24}$ & 3.52 & 2.78 & 63.10 & 44.43 & .09 & .14 & & & .08 & .10 & 5.13 & 4.58 & & \\
\hline$x_{25}$ & 3.11 & 2.89 & 52.63 & 47.26 & .08 & .09 & & & .07 & .06 & 3.82 & 2.99 & & \\
\hline$x_{26}$ & 3.63 & 2.28 & 65.69 & 32.02 & .08 & .08 & & & .06 & .06 & 4.26 & 1.77 & & \\
\hline$x_{27}$ & 2.59 & 3.55 & 39.71 & 63.83 & .06 & .06 & & & .05 & .04 & 1.89 & 2.83 & & \\
\hline$x_{28}$ & 2.65 & 3.35 & 41.17 & 58.70 & .06 & .06 & & & .05 & .05 & 1.96 & 2.64 & & \\
\hline$x_{29}$ & 3.19 & 2.68 & 54.68 & 42.09 & .07 & .03 & & & .06 & .02 & 3.07 & 0.76 & & \\
\hline$x_{210}$ & 2.87 & 3.01 & 46.76 & 50.37 & .11 & .15 & & & .10 & .11 & 4.53 & 5.60 & & \\
\hline$x_{211}$ & 2.96 & 2.89 & 48.99 & 47.26 & .08 & .12 & & & .07 & .09 & 3.52 & 4.12 & & \\
\hline$x_{212}$ & 2.61 & 3.16 & 40.21 & 53.92 & .08 & .14 & & & .07 & .10 & 2.64 & 5.44 & & \\
\hline$x_{213}$ & 2.65 & 3.43 & 41.33 & 60.82 & .06 & .06 & & & .05 & .05 & 2.18 & 2.74 & & \\
\hline$x_{214}$ & 2.43 & 3.19 & 35.68 & 54.68 & .08 & .08 & & & .07 & .06 & 2.35 & 3.22 & & \\
\hline
\end{tabular}




\begin{tabular}{|c|c|c|c|c|c|c|c|c|c|c|c|c|c|c|}
\hline \multirow{2}{*}{$\begin{array}{c}\text { [Construct] } \\
\text { Item }\left(\mathrm{a}_{\mathrm{n}}\right) \\
{\left[\xi_{3}\right]}\end{array}$} & \multicolumn{2}{|c|}{$\mu$} & \multicolumn{2}{|c|}{$\mu_{\text {rescaled }}$} & \multicolumn{2}{|c|}{$\begin{array}{c}\text { Impact }\left(i_{\mathrm{n}}\right) \\
\text { (factor weights) }\end{array}$} & \multicolumn{2}{|c|}{$\begin{array}{l}\text { Sum of factor } \\
\text { weights }\end{array}$} & \multicolumn{2}{|c|}{ Relative impact } & \multicolumn{2}{|c|}{$\begin{array}{c}\text { Weighted PI } \\
\text { per item }\end{array}$} & \multicolumn{2}{|c|}{$\begin{array}{c}\text { (Total) PI } \\
\text { per construct }\end{array}$} \\
\hline & A & DK & A & DK & A & DK & A & DK & A & DK & A & DK & A & DK \\
\hline$x_{31}$ & 4.23 & 2.06 & 80.63 & 26.43 & .05 & .16 & \multirow{8}{*}{1.46} & \multirow{8}{*}{1.38} & .03 & .11 & 2.53 & 2.99 & \multirow{8}{*}{64.62} & \multirow{8}{*}{42.18} \\
\hline$x_{32}$ & 3.37 & 2.90 & 59.13 & 47.46 & .17 & .14 & & & .12 & .10 & 6.95 & 4.82 & & \\
\hline$x_{33}$ & 3.59 & 2.38 & 64.69 & 34.43 & .08 & .10 & & & .05 & .07 & 3.40 & 2.57 & & \\
\hline$x_{34}$ & 4.02 & 2.57 & 75.52 & 39.29 & .21 & .14 & & & .14 & .10 & 10.58 & 4.10 & & \\
\hline$x_{35}$ & 3.27 & 2.82 & 56.76 & 45.56 & .26 & .22 & & & .18 & .16 & 10.00 & 7.27 & & \\
\hline$x_{36}$ & 3.87 & 2.83 & 71.65 & 45.78 & .17 & .13 & & & .12 & .09 & 8.32 & 4.25 & & \\
\hline$x_{37}$ & 3.16 & 3.05 & 53.91 & 51.19 & .23 & .19 & & & .16 & .14 & 8.47 & 6.98 & & \\
\hline$x_{38}$ & 3.75 & 2.69 & 68.73 & 42.29 & .31 & .30 & & & .21 & .22 & 14.37 & 9.20 & & \\
\hline$\left[\eta_{1}\right]$ & $\mathrm{A}$ & DK & $\mathrm{A}$ & DK & $\mathrm{A}$ & DK & $\mathrm{A}$ & DK & A & DK & A & DK & $\mathrm{A}$ & DK \\
\hline$y_{11}$ & 2.84 & 3.09 & 46.01 & 52.25 & .39 & .42 & \multirow{3}{*}{1.05} & \multirow{3}{*}{1.05} & .37 & .40 & 17.09 & 20.95 & \multirow{3}{*}{48.08} & \multirow{3}{*}{49.76} \\
\hline$y_{12}$ & 2.73 & 3.15 & 43.28 & 53.75 & .38 & .33 & & & .36 & .32 & 15.54 & 17.03 & & \\
\hline$y_{13}$ & 3.29 & 2.67 & 57.34 & 41.75 & .28 & .30 & & & .27 & .28 & 15.45 & 11.79 & & \\
\hline
\end{tabular}

Note: $\mu$, mean value; A, Austria; DK, Denmark; PI, performance index; Values were rescaled to a 100-point rating scale (0, lowest possible performance; 100, highest possible performance); Performance Index formula: $\mathrm{PI}=\left\{\left(i_{1} * a_{1}\right)+\left(i_{2} * a_{2}\right)+\ldots\left(i_{\mathrm{n}} * a_{\mathrm{n}}\right)\right\} /\left(i_{1}+i_{2}+\ldots i_{\mathrm{n}}\right)$ (Johnson and Gustafsson, 2000) 


\section{Appendix}

\section{Latent construct}

Indicator ("to what degree...") ...

$\lambda_{n}$
(Baseline
model)

SCM resources [Requirements that are fundamental for originating SCM-related processes and the application of SCM]

\begin{tabular}{|c|c|c|c|c|}
\hline \multicolumn{5}{|c|}{ Internal SCM resources $\left(\xi_{1}\right)$} \\
\hline$x_{11}$ & ....are personnel / human resources made available for SCM issues? & $.931 * * *$ & $.863 * * *$ & $1.082 * * *$ \\
\hline$x_{12}$ & ....are financial resources made available for SCM issues? & $.892 * * *$ & $.892 * * *$ & $.976^{* * *}$ \\
\hline$x_{13}$ & ...does the top management of your company support SCM issues? & $.980 * * *$ & $.937 * * *$ & $.944 * * *$ \\
\hline$x_{14}$ & ...were internal goals set up before SCM projects were launched? & $1.024 * * *$ & $1.069 * * *$ & $.979 * * *$ \\
\hline$x_{15}$ & ....are employees able to use IT systems for SCM issues? & $.949 * * *$ & $1.006 * * *$ & $.816^{* * *}$ \\
\hline$x_{16}$ & $\begin{array}{l}\text {...does your company have IT systems capable of processing data from other supply chain (SC) } \\
\text { members? }\end{array}$ & $.997 * * *$ & $.974 * * *$ & $.999 * * *$ \\
\hline$x_{17}$ & $\begin{array}{l}\text {...is there an agreement on guidelines with respect to the exchange of information with other } \\
\text { companies in the SC? }\end{array}$ & $.848 * * *$ & $.927 * * *$ & $.800 * * *$ \\
\hline$x_{18}$ & ....are employees trained in order to contribute to SCM projects? & $.880 * * *$ & $.938 * * *$ & $.806 * * *$ \\
\hline$x_{19}$ & ...does your company have project groups consisting of people from different functional areas? & $.961 * * *$ & $.946 * * *$ & $.776 * * *$ \\
\hline$x_{110}$ & ...is there the necessary expertise in your company to set up and maintain SC relationships? & $.757 * * *$ & $.683 * * *$ & $.648 * * *$ \\
\hline$x_{111}$ & ...is your company willing to integrate with other SC members? & $.781 * * *$ & $.814 * * *$ & $.562 * * *$ \\
\hline$x_{112}$ & ...is the cross-functional execution of internal business processes important within your company? & $.733 * * *$ & $.530 * * *$ & $.609 * * *$ \\
\hline$x_{113}$ & ....are SC processes evaluated within your company? & $.930 * * *$ & $1.170 * * *$ & $.642 * * *$ \\
\hline
\end{tabular}




\begin{tabular}{|c|c|c|c|c|}
\hline \multicolumn{2}{|c|}{$\begin{array}{l}\text { Latent construct } \\
\text { Indicator ("to what degree...") ... }\end{array}$} & $\begin{array}{c}\lambda_{n} \\
\text { (Baseline } \\
\text { model) }\end{array}$ & $\begin{array}{c}\lambda_{n} \\
\text { (Austria) }\end{array}$ & $\begin{array}{c}\lambda_{n} \\
(\text { Denmark) }\end{array}$ \\
\hline \multicolumn{5}{|c|}{ SCM resources [Requirements that are fundamental for originating SCM-related processes and the application of SCM] } \\
\hline$x_{21}$ & .... are SC processes evaluated together with other SC members? & $.937 * * *$ & $1.013 * * *$ & $.726 * * *$ \\
\hline$x_{22}$ & ...is there an agreement on collaborative goals with other SC members? & $.964 * * *$ & $.976^{* * *}$ & $.907 * * *$ \\
\hline$x_{23}$ & ... are there SC project groups in place with other SC members? & $.957 * * *$ & $1.033 * * *$ & $.782 * * *$ \\
\hline$x_{24}$ & ...is your company aware that its decisions may affect other SC members? & $.817 * * *$ & $.830 * * *$ & $.901 * * *$ \\
\hline$x_{25}$ & ...is your company willing to trust other SC members? & $.752 * * *$ & $.810 * * *$ & $.665^{* * *}$ \\
\hline$x_{26}$ & ...does your company have long-term relationships with other SC members? & $.634 * * *$ & $.783 * * *$ & $.457 * * *$ \\
\hline$x_{27}$ & ...is there an equal distribution of power among all members of your SC? & $.557 * * *$ & $.573 * * *$ & $.455^{* * *}$ \\
\hline$x_{28}$ & $\begin{array}{l}\text {...is the distribution of risks and benefits even between your company and other members of your } \\
\text { SC? }\end{array}$ & $.573 * * *$ & $.605 * * *$ & $.451 * * *$ \\
\hline$x_{29}$ & ...is there mutual dependency between your company and other members of your SC? & $.542 * * *$ & $.708 * * *$ & $.247 * * *$ \\
\hline$x_{210}$ & ...does your company exchange information regarding stock levels with other SC members? & $1.056 * * *$ & $1.136 * * *$ & $.902 * * *$ \\
\hline$x_{211}$ & ...does your company exchange forecasting information with other SC members? & $.920 * * *$ & $.989 * * *$ & $.796 * * *$ \\
\hline$x_{212}$ & ...does your company exchange product development information with other SC members? & $.794 * * *$ & $.761 * * *$ & $.839 * * *$ \\
\hline$x_{213}$ & ...is your corporate culture similar to that of other SC members? & $.640 * * *$ & $.699 * * *$ & $.452 * * *$ \\
\hline$x_{214}$ & ...is your corporate decision making similar to that of other SC members? & $.645^{* * *}$ & $.696 * * *$ & $.482 * * *$ \\
\hline
\end{tabular}




\begin{tabular}{|c|c|c|c|}
\hline $\begin{array}{l}\text { Latent construct } \\
\text { Indicator ( "to what degree...") ... }\end{array}$ & $\begin{array}{c}\lambda_{n} \\
\text { (Baseline } \\
\text { model) }\end{array}$ & $\begin{array}{c}\lambda_{n} \\
\text { (Austria) }\end{array}$ & $\begin{array}{c}\lambda_{n} \\
\text { (Denmark) }\end{array}$ \\
\hline
\end{tabular}

Capability to adopt SCM-related processes $\left(\xi_{3}\right)$ [processes that integrate or coordinate different key business areas within the firm and between the firm's suppliers and customers and create customer value]

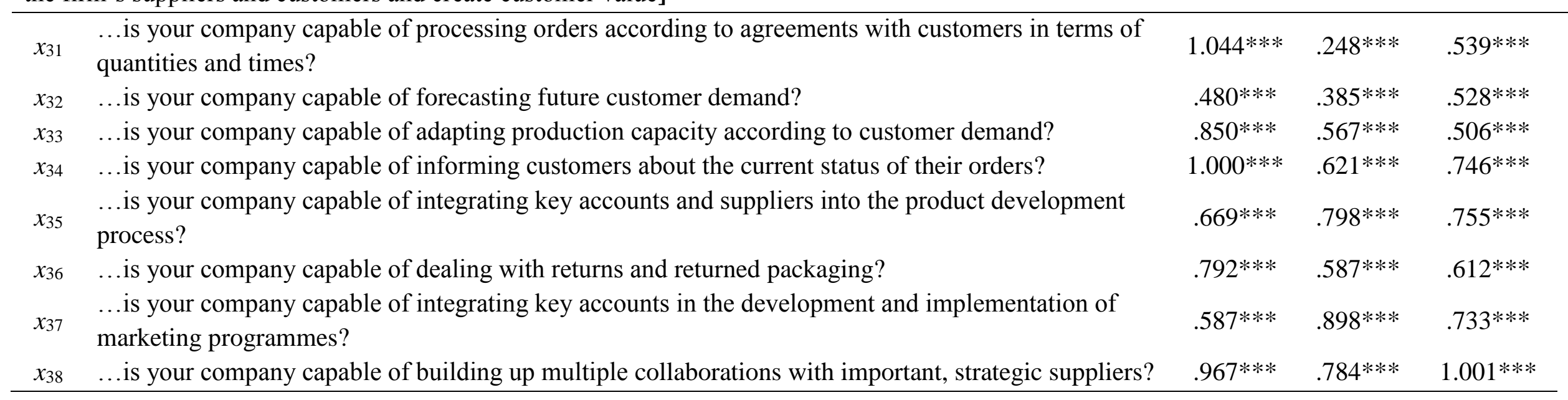




\section{Latent construct}

Indicator ( "to what degree...") ...

$\begin{array}{ccc}\lambda_{n} & \lambda_{n} & \lambda_{n} \\ \begin{array}{c}\text { (Baseline } \\ \text { model) }\end{array} & \text { (Austria) } & \text { (Denmark) }\end{array}$

SCM execution ( $\left.\boldsymbol{\eta}_{1}\right)$ [The firm's internal and external integration of business processes with suppliers and customers, which generates a flow of products, services and related information for creating value and for improving the total performance of the chain.]

\begin{tabular}{|c|c|c|c|c|}
\hline$y_{11}$ & $\begin{array}{l}\text {...has your company integrated sourcing, logistics, marketing, product development and other areas } \\
\text { with your suppliers? }\end{array}$ & $1.024 * * *$ & $.963 * * *$ & $1.116 * * *$ \\
\hline
\end{tabular}

Note: $x, y$, indicator/manifest variable; $\boldsymbol{\xi}, \eta$, factor/latent variable/construct; $\lambda_{n}$, factor loadings; ratings based on a five-point scale, verbally and numerically anchored ( 1 , to a very low degree; 5 , to a very high degree); 